\title{
Review of Grain Fortification Legislation, Standards, and Monitoring Documents
}

\author{
Kristin J. Marks, ${ }^{a, b}$ Corey L. Luthringer, ${ }^{c}$ Laird J. Ruth, ${ }^{a, d}$ Laura A. Rowe, ${ }^{e}$ Noor A. Khan, ${ }^{f}$ Luz María De-Regil, \\ Ximena López, ${ }^{9}$ Helena Pachón ${ }^{a, b}$
}

The majority of countries with mandatory grain fortification requirements document the technical specifications for grain fortification, such as allowable food vehicles and fortification levels required. Most document systems for monitoring. However, detailed protocols, descriptions of roles and responsibilities, means to support the cost of regulation, enforcement strategies, and methods for reporting monitoring results to stakeholders are generally lacking.

\section{ABSTRACT}

Objective: Analyze the content of documents used to guide mandatory fortification programs for cereal grains.

Methods: Legislation, standards, and monitoring documents, which are used to mandate, provide specifications for, and confirm fortification, respectively, were collected from countries with mandatory wheat flour $(n=80)$, maize flour $(n=11)$, and/or rice $(n=6)$ fortification as of January 31, 2015, yielding 97 possible country-grain combinations (e.g., Philippines-wheat flour, Philippines-rice) for the analysis. After excluding countries with limited or no documentation, 72 reviews were completed, representing 84 country-grain combinations. Based on best practices, a criteria checklist was created with 44 items that should be included in fortification documents. Two reviewers independently scored each available document set for a given country and food vehicle (a country-grain combination) using the checklist, and then reached consensus on the scoring. We calculated the percentage of country-grain combinations containing each checklist item and examined differences in scores by grain, region, and income level.

Results: Of the 72 country-grain combinations, the majority of documentation came from countries in the Americas $(46 \%)$ and Africa $(32 \%)$, and most were from upper and lower middle-income countries $(73 \%)$. The majority of country-grain combinations had documentation stating the food vehicle(s) to be fortified $(97 \%)$ and the micronutrients (e.g., iron) (100\%), fortificants (e.g., ferrous fumarate) $(88 \%)$, and fortification levels required $(96 \%)$. Most $(78 \%)$ stated that labeling is required to indicate a product is fortified. Many country-grain combinations described systems for external $(64 \%)$ monitoring, and stated that industry is required to follow quality assurance/quality control (64\%), though detailed protocols (33\%) and roles and responsibilities (45\%) were frequently not described.

Conclusions: Most country-grain combinations have systems in place for internal, external, and import monitoring. However, documentation of other important items that would influence product compliance to national standard, such as roles and responsibilities between agencies, the cost of regulating fortification, and enforcement strategies, are often lacking. Countries with existing mandatory fortification can improve upon these items in revisions to their documentation while countries that are beginning fortification can use the checklist to assist in developing new policies and programs.

\section{INTRODUCTION}

arge-scale fortification of staple foods is a costeffective and sustainable strategy for substantially reducing micronutrient malnutrition. ${ }^{1}$ The fortification of cereal grains with folic acid, iron, zinc, vitamin B12, niacin,

\footnotetext{
aFood Fortification Initiative, Atlanta, GA, USA.

${ }^{b}$ Emory University, Atlanta, GA, USA.

${ }^{\circ}$ Global Alliance for Improved Nutrition, Geneva, Switzerland.

dU.S. Centers for Disease Control and Prevention, Atlanta, GA, USA

eProject Healthy Children, Cambridge, MA, USA.

${ }^{f}$ Nutrition International, OHtawa, Canada.

${ }^{9}$ Granotec, Santiago, Chile.

Correspondence to Kristin J. Marks (kristin.marks@emory.edu).
}

riboflavin, thiamin, vitamin $\mathrm{A}$, and other micronutrients has gained global traction as a strategy to improve human health. Fortification has led to reduced incidence of neural tube defects ${ }^{2,3}$ and nutritional anemia, ${ }^{4}$ among other health outcomes. According to the Food Fortification Initiative, in 2016, 34\% of industrially milled wheat flour, $57 \%$ of industrially milled maize flour, and $1 \%$ of industrially milled rice was fortified $(71 \%, 29 \%$, and $45 \%$ of wheat flour, maize flour, and rice, respectively, was industrially milled), and 87 countries mandated the fortification of at least one of these cereal grains. ${ }^{5}$

For governments to ensure effective food fortification, enactment of laws and regulations provide legal 
authority and a regulatory framework. ${ }^{1}$ Mandatory fortification, as compared to voluntary, is more likely to achieve and sustain the desired health benefits of fortification., 3 The regulatory framework specific to food fortification provides the basis for ensuring the quality and safety of products and for meeting public health nutrition objectives. ${ }^{7,8}$ Practical implementation of fortification is challenging though, as evidenced by global insufficient compliance against fortification standards. ${ }^{7}$ Therefore, periodic government monitoring will help determine whether program objectives are being met.

Given the challenges of implementing largescale, cereal-grain fortification, effective legislation, standards, and monitoring documents can provide clear guidance on key program decisions, activities, and milestones such as the micronutrients/premix required; financial responsibility of implementing and monitoring and enforcing fortification; labeling of fortified products; internal, external, commercial, and import monitoring procedures; incentives and penalties; laboratory methods; and reporting guidelines. ${ }^{1,8-23}$ The objectives of this review are to assess the content of legislation, standards, and monitoring documents used to guide mandatory cereal grain fortification programs in countries and to identify areas of strength and areas needing improvement. To the best of our knowledge, there has never been a review of cereal-grain legislation, standards, and monitoring documents' content conducted at global scale. Previous work has looked at individual regions or a handful of countries, has been limited to one food vehicle, and has rarely included monitoring documents. ${ }^{8,10,21,24}$

\section{METHODS}

\section{Document Inclusion Criteria}

Any country that had mandatory fortification of wheat flour, maize flour, or rice as of January 31, 2015, was included in this review. We defined mandatory fortification of cereal grains as "country has legislation that has the effect of mandating fortification of one or more types of wheat or maize flour or rice with at least iron or folic acid." ${ }^{5}$ Under this definition, as of January 2015, 80 countries mandated wheat flour fortification, 11 mandated maize flour fortification, and 6 mandated rice fortification. This yielded a maximum of 97 possible country-grain combinations for the analysis (e.g., Philippines-wheat flour was one combination and Philippines-rice was another).
Documents included in our study consist of legislation and statutory instruments, standards, technical regulations and specifications, and monitoring guidelines (Box). Legislation and statutory instruments typically mandate national or regional fortification of the specified cereal grain and include initial legislation such as the food act (may also be known as the food and drug act or food control act) ${ }^{1,17}$; hereafter, we refer to these as legislation documents. Standards, technical regulations, and specifications typically provide any implementing rules, regulations, or guidelines, such as dictating which vitamins and minerals to include in fortification and the levels of each nutrient to be added, as well as packaging and labeling requirements $^{1,17}$; hereafter, we refer to these as standards documents. Monitoring guidelines ensure that quality control measures are followed routinely and problems are corrected so that fortified products consistently abide by relevant standards and fortification achieves its maximum health impact ${ }^{1,17}$; hereafter, we refer to these as monitoring guidelines.

Four monitoring categories were included in this analysis: internal, external, commercial, and import level. ${ }^{1}$ As part of internal monitoring, food processors use quality assurance and quality control procedures to ensure consistent production of quality fortified food. ${ }^{11}$ In external and import monitoring, government authorities periodically inspect and audit processes and test products at production and import sites, respectively, to

\section{As of January 2015, 80 countries mandated wheat flour fortification, 11 mandated maize flour fortification, and 6 mandated rice fortification.}

BOX. Description of Legislation, Standards, and Monitoring Documents ${ }^{a}$ Legislation: establishes the legal framework and broad principles for fortification

Examples include:

- Statutory instruments

- Food law

Standards: mandate the specific legal requirements for food fortification Examples include:

- Technical regulations

- Specifications

Monitoring documents: provide instructions to track the operational performance of a fortification program

Examples include:

- Manuals

- Guidelines

- Procedures

${ }^{a}$ Adapted from Allen et al. (2006) ${ }^{1}$ and Nathan (1999). ${ }^{17}$ 


\section{We completed \\ 72 reviews representing 84 country-grain combinations.}

ensure that fortification meets the country's specifications. ${ }^{1}$ As part of commercial monitoring, food safety inspectors check retail outlets to be sure the fortified product is in the marketplace and complies with regulations on packaging and labeling. ${ }^{21}$

In addition to the 3 main types of documents included (legislation, standards, and monitoring guidelines), we included the following document types when applicable: updates or amendments to legislation or standards; documents that are referenced by the legislation, standards, or monitoring guidelines; and reports of monitoring results. We recognize that countries have different legal systems, resulting in laws and regulations taking different forms; therefore, this review examines legislation, standards, and monitoring documents collectively and uses broad inclusion criteria for documents. ${ }^{17}$

Of the 97 possible country-grain combinations, there were 7 countries with no documentation available (Benin, Guinea, Iran, Mali, Mauritania, Niger, and Saudi Arabia) (Figure 1). In 6 countries (Bahrain, Iraq, Jordan, Nepal, Oman, and Yemen), very limited documents were available so they were also excluded. Thirteen Caribbean countries follow the Caribbean Community and Common Market (CARICOM) standard ${ }^{25}$ and have no additional documentation; therefore, we reviewed these countries as a whole (Antigua and Barbuda, Bahamas, Barbados, Dominica, Grenada, Guyana, Haiti, Jamaica, Saint Kitts and Nevis, Saint Lucia, Saint Vincent and the Grenadines, Suriname, and Trinidad and Tobago). In summary, we completed 72 reviews representing 84 country-grain combinations (Supplement Table 1).

\section{Document Collection}

Documents included in the analysis were primary sources collected in a variety of ways. First, we gathered documents from internal databases within partner agencies, such as the Food Fortification Initiative (FFI), the Global Alliance for Improved Nutrition (GAIN), Project Healthy Children (PHC), and Nutrition International, that support countries with their fortification programs. Second, we sent requests for documents to contacts for all countries mandating grain fortification in September 2014 and September 2015 to fill any known gaps. ${ }^{4,26}$ We also emailed and called Ministries of Health and other relevant agencies within countries to procure documents. If documents were in a language other than English or Spanish, they were translated to English.

FIGURE 1. Flowchart of Country-Grain Combination ${ }^{a}$ Exclusions

97 possible country-grain combinations $s^{\mathrm{a}}$ as of January 31,2015

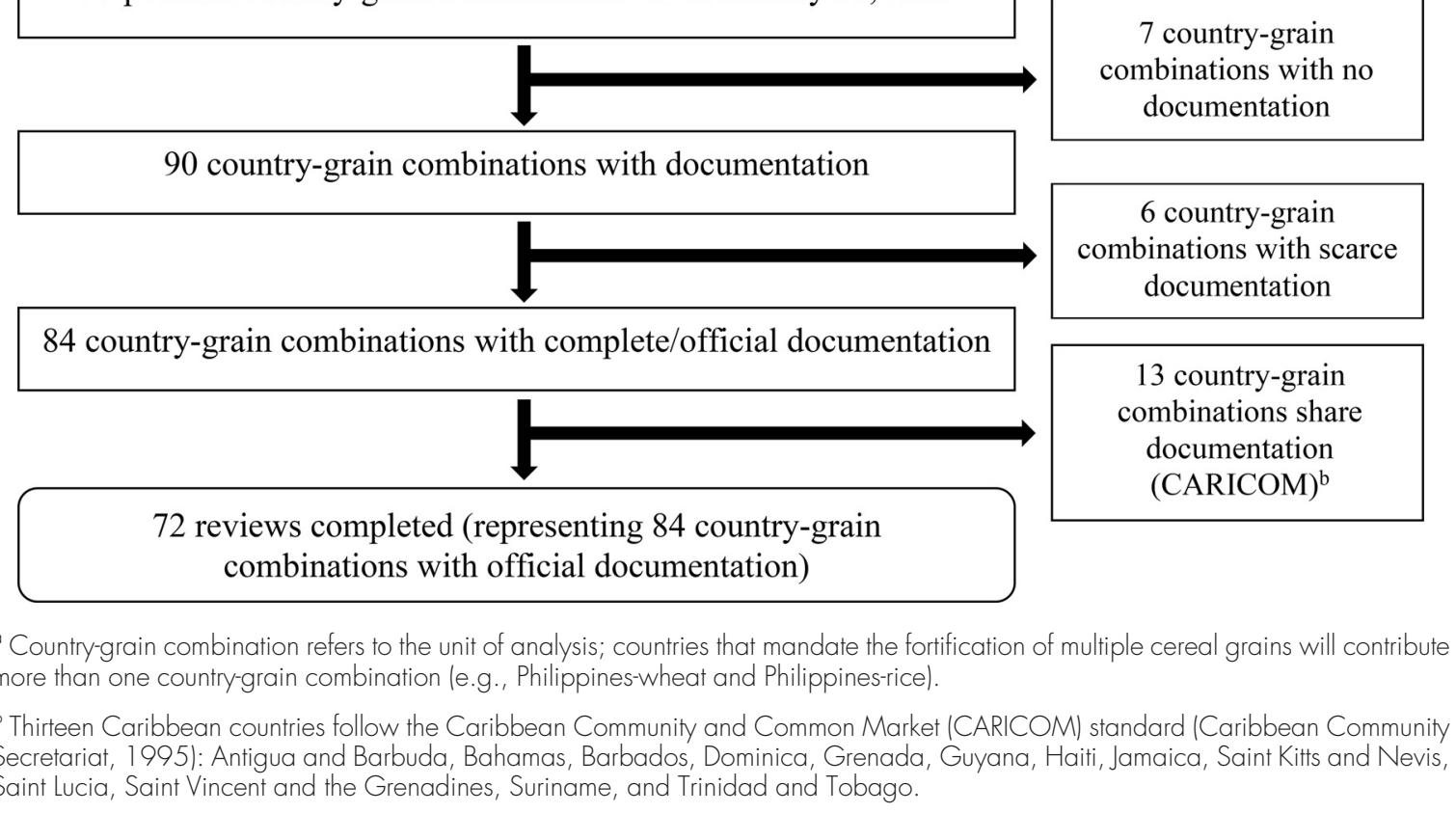




\section{Framework Development}

To evaluate the contents of a set of documents, where a set is the legislation, standards, and/or monitoring guidelines for a given country-grain combination, we developed a checklist of items that should be ideally included in a set of fortification documents. ${ }^{1,8-23}$ We determined the checklist items through a literature review conducted in February and March 2015 using PubMed and Google Scholar (keywords included combinations of food fortification, legislation, standards, monitoring, evaluation, framework). The checklist was then revised by content experts, who also suggested pertinent studies for consideration. As part of the literature review, studies of legislation surrounding mandatory or voluntary fortification of any food vehicle were included, specifically studies of legislation for industrial fortification (as opposed to home-based fortification, which employs the use of a supplement, not fortified food). Legislative frameworks for fortification and case studies of legislation development or monitoring procedures were also included. Manuals for legislation, standards, and enforcement of food law and fortification, as well as manuals developed for implementing components of a fortification program, were also included in the literature review. Lastly, we included any studies that contained suggestions for model laws or any studies on monitoring of fortification programs.

We piloted the criteria checklist with a subset of 11 country-grain combinations. Following the pilot, we pared down the checklist and focused on items relevant to fortification (as opposed to general food control measures). The final version of the criteria checklist contained 44 items categorized as general, micronutrients/premix, costing, labeling, internal monitoring, external monitoring, commercial monitoring, import monitoring, enforcement/penalties, laboratory testing, and reporting (Table 1).

\section{Document Review}

Two reviewers independently reviewed a set of documents for a given country-grain combination and came to a consensus on the scoring of the 44 items. All coauthors conducted the reviews ( 8 reviewers in total); the 3 reviewers involved in the development of the checklist and the pilot (KJM, CLL, HP) were paired with the other 5 reviewers to ensure consistency across reviews. Three reviewers (XL, LMD-R, HP) reviewed the Spanish-language sets in Spanish. Reviewers completed the checklist by scoring each item using "does not contain item" or "contains item in its totality." About one-third of items on the checklist $(n=15)$ also had "contains item to some degree" as an option. One-quarter of items on the checklist $(n=10)$ had "not applicable" as an option. There was a comment field adjacent to each item for qualitative observations. If there was a discrepancy in the scoring between reviewers that the pair could not come to consensus on, a third-person arbiter resolved it.

\section{Country Outreach}

After we completed reviews in June 2016, we reached out to in-country contacts, particularly National Fortification Alliance members, via email for all countries included in the review to confirm that all appropriate documentation was included in the review and that preliminary reviews seemed accurate for the given documentation. If documentation was missing and then sent by contacts, we completed a second review including the additional documentation.

\section{Data Analysis}

For each item in the checklist, we calculated the percentage of countries with documentation that fully contained that item. Country-grain combinations receiving a score of "not applicable" for an item were removed from the denominator for that item. We also examined differences in scores by grain, by region, ${ }^{27}$ and by income level. ${ }^{28} \mathrm{We}$ conducted a sensitivity analysis, using chi-square tests, to gauge whether the completeness of the documentation reviewed differed between those countries that responded to the country outreach efforts and verified completeness of documentation versus those that did not. Qualitatively, we extracted clear and flexible passages from documents that illustrated language that fully contained each item of interest.

\section{RESULTS}

Of the 72 country-grain combinations reviewed, $55(76 \%)$ were of wheat flour, $11(15 \%)$ of maize flour, and $6(8 \%)$ of rice. The majority of documentation came from countries in the Americas $(46 \%, \mathrm{n}=33)$ and Africa $(32 \%, \mathrm{n}=23)$. Among those with wheat flour documentation, the countries were mainly from the Americas $(42 \%, \mathrm{n}=23)$ and Africa $(33 \%, \mathrm{n}=18)$, with Europe $(13 \%, \mathrm{n}=7)$, the Pacific $(5 \%, \mathrm{n}=3)$, Asia $(4 \%, \mathrm{n}=2)$, and the Middle East $(4 \%, n=2)$ contributing a smaller proportion. Among those with maize flour documentation, $55 \%$ was from the Americas $(n=6)$ and $45 \%$ from

\section{We developed a checklist of 44 items that should be ideally included in a set of fortification documents.}

\section{Most of the documentation we reviewed came from countries in the Americas and Africa.}


TABLE 1. Checklist of Key Items ${ }^{a}$ and All Possible Scoring Options in Fortification Legislation, Standards, and Monitoring Documents

Item

\section{Scoring Options}

\section{References}

\section{General}

1. States that legislation applies to at least one food vehicle fit for human consumption (types/ grades to be fortified)

2. States the public health objective; purpose and scope of legislation

\section{References latest available science or accepted} international norms and recommendations, particularly for items that may not be covered in the country's documents

\section{Provides definitions that include terms that are} specific to fortification (e.g., fortified food, premix, fortificant, food vehicle)

\section{Provides repeals (if there is at least one prior document about fortification)}

6. Provides effective date or gives grace period for when fortification is to begin (e.g., effective 6 months from signing)

\section{Micronutrients/Premix}

7. States nutrients required

8. States fortificants (chemical compounds) to be used (including fortificants that are allowable as options)

9. States fortification levels
10. States consideration of bioavailability/bio-
logical activity of fortificants

11. States consideration of nutrient stability

\section{Costing}

12. States that the cost of fortification is regulated through cost-sharing schemes (between government, industry, consumers) or tax measures (to assist industry)

\section{States consideration of the financial responsi-} bility (of the government) of monitoring and enforcing fortification (schedule of fees, budget)

\section{Labeling}

14. Includes some sort of statement/label/logo that makes it clear that the product is fortified

\section{Provides guidance on health claims that can} be made for this product (specific to micronutrients added through fortification)

\section{(2) States at least one type fit for human consumption}

(0) Does not state

(2) States the public health objective or general purpose of legislation

(0) Does not state
(2) States the documents referenced
$12,17,21$

(0) Does not state

(2) States at least one term related to fortification

17,22

(0) Does not state

(2) States repeals

(0) Does not state

(N/A) No prior documents about fortification

(2) States effective date or grace period for when fortification is to begin (e.g., effective 6 months from signing)

(0) Does not state

(2) States nutrients

$8,10,12,13,21$

(0) Does not state

(2) States fortificants for at least one nutrient $8,10,12,13,21$

(0) Does not state

(2) States a range or number with $+/$ -

$8,10,13,21$

(1) States one number only

(0) Does not state

(2) States some consideration of bioavailability (mentions these or related terms)

(0) Does not state any consideration

(2) States consideration of nutrient stability

(0) Does not state any consideration

(2) States consideration of either cost regulation

$10,12,13$ method

(0) Does not state any consideration

(2) Shows consideration that monitoring costs money

$10,13,19,21,22$

(2) Shows consideration that monito
(0) Does not state any consideration

(2) Includes a statement, label, or logo

$8,10,12,13,18$

(0) Does not include statement, label, or logo

(2) Provides guidance on health claims specific to micronutrients added through fortification

(0) Does not provide 
TABLE 1. Continued

Item

Scoring Options

References

Internal Monitoring (Conducted by Industry)

16. States requirement for sampling as part of internal monitoring (e.g., describing number of samples, amount, frequency, individual vs. composite, where samples are taken in the process, and percent considered passing)

17. States that industry is required to follow quality assurance/quality control in regards to fortification

18. States applicability of using qualitative testing (e.g., spot tests, iChecks) to determine the presence or absence of a vitamin or mineral

\section{External Monitoring (Conducted by Government)}

19. States requirement for external monitoring at the production site to assure compliance with standards and regulations

20. Describes protocols and systems for regulatory monitoring

21. If there are two or more government agencies involved in external monitoring, clarifies the roles and responsibilities between different government agencies in external monitoring

22. Allows for monitoring to be conducted often enough that problems can be identified and addressed on a timely basis; specifies a timeline for inspections (e.g., once every 6 months, increasing to once every 2 months if a discrepancy is found)

23. States requirement for sampling as part of external monitoring (e.g., describing number of samples, amount, frequency, individual vs. composite, where samples are taken in the process, and percent considered passing)

24. States applicability of using qualitative testing (e.g., spot tests, iChecks) to determine the presence or absence of a vitamin or mineral

25. States registration is required in order to use a logo/be licensed to produce fortified foods
(2) States that samples should be taken as part of in-

$1,8,12,22,23$ ternal monitoring

(1) States that samples should be taken (generally)

(0) States that samples should not be taken

(N/A) Does not describe the sampling process

(2) States requirement of quality assurance/quality

$1,8,12,22,23$ control for fortification

(0) Does not state requirement

(2) States applicability of spot test to determine pres-

11,21 ence/absence of vitamin or mineral specific to internal monitoring

(1) States applicability of spot test to determine presence/absence of vitamin or mineral generally

(0) Does not state

(2) States requirement for external monitoring or the

$1,9,10,12,15,17,18,21,22,23$ need for audits/inspections

(0) Does not state requirement

(2) Includes checklists or provides detailed description

$1,13,21$ of regulatory monitoring procedures

(1) Does not explicitly describe, but references proto-

cols and systems for regulatory monitoring

(0) Does not describe

(2) Clarifies roles and responsibilities for more than

$12,21,23$ one agency

(1) Clarifies roles and responsibilities for one agency

(O) Clarifies roles and responsibilities for no agencies

(N/A) Only one government agency involved

(2) Describes frequency and how it is responsive to the $1,16,18,23$ needs of industry or the stage of fortification implementation

(1) Makes mention of a timeline

(0) Does not state

(2) States that samples should be taken as part of $1,8,12,22,23$ external monitoring

(1) States that samples should be taken (generally)

(0) States that samples should not be taken

(N/A) Does not describe the sampling process

(2) States applicability of spot test to determine presence/absence of vitamin or mineral specific to external monitoring

(1) States applicability of spot test to determine presence/absence of vitamin or mineral generally

(0) Does not state

(2) Describes some type of registration or licensing

17,18

(0) Does not state that registration or licensing is required 
TABLE 1. Continued

Item

Scoring Options

References

Commercial Monitoring (Conducted by

Government)

26. Provides justification for commercial monitoring at retail stores

(2) Provides justification for commercial monitoring

27. Describes protocols and systems for commer-

cial monitoring

(0) Does not provide justification for commercial monitoring

(2) Includes checklists or provides detailed description

commercial monitoring procedures

(1) Does not explicitly describe, but references protocols and systems for commercial monitoring

(0) Does not describe

28. If there are two or more government agencies involved in commercial monitoring, clarifies the roles and responsibilities between different government agencies in commercial monitoring

29. Allows for monitoring to be conducted often enough that problems at the production site or import companies can be identified and addressed on a timely basis; specifies a timeline for inspections (e.g., once every 6 months) or works with production companies to correct noncompliance

30. States requirement for sampling as part of commercial monitoring (e.g., describing number of samples, amount, frequency, individual vs. composite, where samples are taken in the process, and percent considered passing)

(2) Clarifies roles and responsibilities for more than $12,21,23$ one agency

(1) Clarifies roles and responsibilities for one agency

(0) Clarifies roles and responsibilities for no agencies

(N/A) Only one government agency involved

(2) Describes frequency and how it is responsive to the

$1,16,18,23$ needs of industry or the stage of fortification implementation

(1) Makes mention of a timeline

(0) Does not state

(N/A) No commercial monitoring occurs

(2) States that samples should be taken as part of

$1,8,12,22,23$ commercial monitoring

(1) States that samples should be taken (generally)

(0) States that samples should not be taken

(N/A) Does not describe the sampling process

\section{Import Monitoring (Conducted by Government)}

31. Provides justification for import monitoring at points of entry

\section{Describes protocols and systems for import} monitoring

33. If there are two or more government agencies involved in import monitoring, clarifies the roles and responsibilities between different government agencies in import monitoring

\section{States requirement for sampling as part of} import monitoring (e.g., describing number of samples, amount, frequency, individual vs. composite, where samples are taken in the process, and percent considered passing)

\section{Enforcement/Penalties}

35. Indicates roles and responsibilities in enforcing the legislation
(2) Provides justification for import monitoring

(0) Does not provide justification for import monitoring

(2) Includes checklists or detailed description of import monitoring procedures

(1) Does not explicitly state, but references protocols and systems for import monitoring

(0) Does not state

(2) Clarifies roles and responsibilities for more than

$12,21,23$ one agency

(1) Clarifies roles and responsibilities for one agency

(0) Clarifies roles and responsibilities for no agencies

(N/A) Only one government agency involved

(2) States that samples should be taken as part of import monitoring

(1) States that samples should be taken (generally)

(0) States that samples should not be taken

(N/A) Does not describe the sampling process

\section{$1,13,2$}

(2) States the role and responsibilities of government in enforcement

(0) Does not state 
TABLE 1. Continued

\begin{tabular}{|c|c|c|}
\hline Item & Scoring Options & References \\
\hline 36. States incentives to start fortification & $\begin{array}{l}\text { (2) States any incentives to encourage fortification ini- } \\
\text { tiation (e.g., tax incentives for new equipment or pre- } \\
\text { mix) } \\
\text { (0) Does not state }\end{array}$ & $13,17,22$ \\
\hline $\begin{array}{l}\text { 37. States incentives to continue fortification, } \\
\text { including ensuring compliance }\end{array}$ & $\begin{array}{l}\text { (2) States any incentives to encourage the continuation } \\
\text { of fortification (e.g., transport priority, favorable tax } \\
\text { or tariff treatment, or patent rights) } \\
\text { (0) Does not state }\end{array}$ & $13,17,22$ \\
\hline 38. States penalties to compel compliance & $\begin{array}{l}\text { (2) States any penalties } \\
\text { (0) Does not state }\end{array}$ & $12,13,14,17,22$ \\
\hline $\begin{array}{l}\text { 39. Penalties are objectively defined (e.g., first } \\
\text { penalty }=\$ 100 \text {, second penalty }=\$ 300 \text { ) }\end{array}$ & $\begin{array}{l}\text { (2) Penalties are objectively laid out in the document } \\
\text { (e.g., first penalty }=\$ 100 \text {, second penalty }=\$ 300 \text { ) } \\
\text { (0) Penalties are not objectively laid out } \\
\text { (N/A) No penalties are stated (answered } 0 \text { to previ- } \\
\text { ous question) }\end{array}$ & 10 \\
\hline \multicolumn{3}{|l|}{ Laboratory } \\
\hline $\begin{array}{l}\text { 41. References required analytical assays for } \\
\text { nutrients (e.g., liquid chromatography-mass spec- } \\
\text { trometry for folic acid, atomic absorption for iron } \\
\text { and zinc) }\end{array}$ & $\begin{array}{l}\text { (2) References required assays } \\
\text { (0) Does not state requirements }\end{array}$ & 8 \\
\hline $\begin{array}{l}\text { 42. States recognition that laboratory results are } \\
\text { subject to several sources of variation and do not } \\
\text { provide conclusive evidence of compliance or } \\
\text { noncompliance }\end{array}$ & $\begin{array}{l}\text { (2) States recognition that lab results are subject to } \\
\text { variation } \\
\text { (0) Does not state recognition }\end{array}$ & 21 \\
\hline $\begin{array}{l}\text { 43. Focuses on the quantitative analysis of marker } \\
\text { micronutrients such as iron }\end{array}$ & $\begin{array}{l}\text { (2) Focuses on quantitative analysis of marker micro- } \\
\text { nutrient such as iron } \\
\text { (0) Does not state }\end{array}$ & $12,21,23$ \\
\hline
\end{tabular}

${ }^{a}$ As identified in the literature and by content experts.

Africa $(n=5)$. The majority of rice documentation was also from the Americas $(67 \%, n=4)$, though the Asia and Pacific regions also contributed documentation $(17 \%, \mathrm{n}=1$ each). The majority of documentation came from upper middle-income countries $(33 \%, \mathrm{n}=24)$ and lower middle-income countries $(40 \%, \mathrm{n}=29)$, with low-income countries contributing $13 \%(\mathrm{n}=9)$ and high-income countries contributing $14 \%(n=10)$ of documentation (based on World Bank classification of countries by income ${ }^{28}$ ). Most documentation was originally in English $(42 \%, \mathrm{n}=30)$ or Spanish $(35 \%, n=25)$.

On average, $46 \%$ of checklist items were fully present in reviews. When examining median scores by grain, maize flour scores were higher $(58 \%)$ than rice $(45 \%)$ and wheat flour $(44 \%)$ scores (Figure 2 ). The median scores by region showed some variability, with Asia scoring the highest (63\%), followed by Africa $(50 \%)$, Europe $(50 \%)$, the Pacific $(48 \%)$, the Americas (45\%), and the Middle East $(17 \%)$ (Figure 3). Comparing scores by income classification, the median scores for high income $(45 \%)$, upper middle-income $(43 \%)$, and lower middle-income $(48 \%)$ were very similar, while low-income countries had a notably higher median score $(80 \%)$ (Figure 4$)$.

Documentation for every country-grain combination $(100 \%, N=72)$ stated the nutrients required to be added through fortification (Table 2).

\author{
On average, \\ $46 \%$ of checklist \\ items were fully \\ present in our \\ document review.
}


FIGURE 2. Median Country-Grain Combination Scores ${ }^{a}$ by Cereal Grain in Countries With Mandatory CerealGrain Fortification

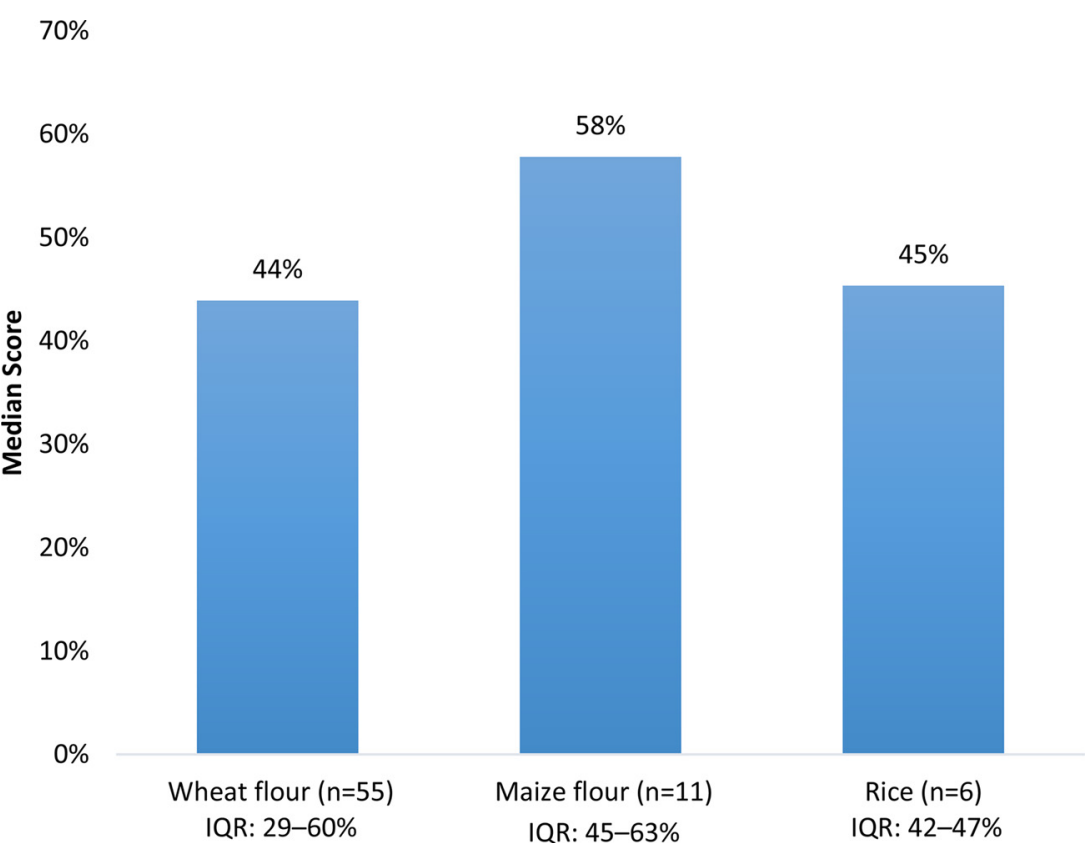

Abbreviation: $I Q R$, interquartile range.

a Country-grain combination refers to the unit of analysis; countries that mandate the fortification of multiple cereal grains will contribute more than one country-grain combination (e.g. Philippines-wheat and Philippines-rice). Scores based on number of checklist items fully documented out of total applicable checklist items.

While $64 \%$ of
country-grain
combinations
documented the
requirement for
external
monitoring at the
production site,
only $33 \%$ provided
a detailed
description of the
monitoring
protocols and
systems.

The fortification levels of those nutrients were stated by $96 \%$ of country-grain combinations; $54 \%$ stated one number, whereas $42 \%$ stated an allowable range. The majority $(88 \%)$ of countrygrain combinations stated at least one fortificant to be used for fortification (e.g., type of iron compound). Documentation for country-grain combinations was also relatively abundant for other general items commonly found in legislation and standards documents: stating the food vehicle to be fortified $(97 \%)$, labeling as fortified food $(78 \%)$, providing definitions to terms specific to fortification $(76 \%)$, and providing the effective date or giving a grace period for when fortification is to begin $(72 \%)$.

Documentation of monitoring procedures among country-grain combinations was less common (Table 2). About two-thirds (64\%) of country-grain combinations stated that industry is required to conduct quality assurance/quality control as part of internal monitoring and $29 \%$ described the applicability of qualitative (spot) tests. Of countries that included a sampling protocol, $71 \%$ of country-grain combinations clearly outlined a sampling process for internal monitoring. The requirement for external monitoring at the production site was documented for $64 \%$ of country-grain combinations; $33 \%$ of country-grain combinations provided a detailed description of external monitoring protocols and systems. The same pattern held for commercial and import monitoring: while $47 \%$ and $64 \%$ of country-grain combinations stated a requirement for commercial and import monitoring, respectively, $19 \%$ and $35 \%$ described the protocols for commercial and import monitoring in detail.

Similarly, $68 \%$ of country-grain combinations stated there were penalties to compel compliance, yet of these, only $31 \%$ laid out objectively defined penalties (e.g., first penalty $=\$ 100$, second penalty $=\$ 300$ ) (Table 2). Furthermore, only $18 \%$ of country-grain combinations stated that enforcement should include feedback and support to improve performance and correct noncompliance. Very few (14\%) country-grain combinations 
FIGURE 3. Median Country-Grain Combination Scores ${ }^{a}$ by Geographic Region in Countries With Mandatory Cereal-Grain Fortification

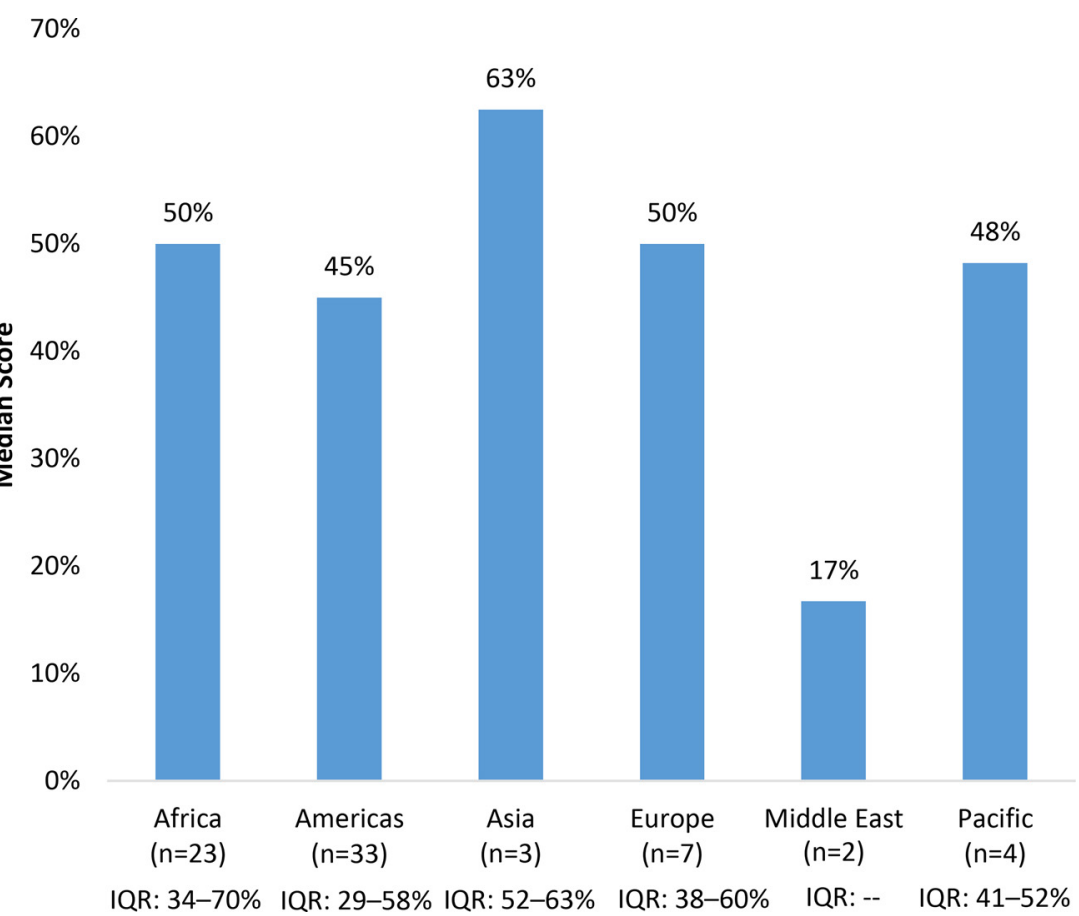

Abbreviation: IQR, interquartile range.

a Country-grain combination refers to the unit of analysis; countries that mandate the fortification of multiple cereal grains will contribute more than one country-grain combination (e.g. Philippines-wheat and Philippines-rice). Scores based on number of checklist items fully documented out of total applicable checklist items.

stated that they provide incentives to start fortification (e.g., reduction of taxes for fortification equipment) and fewer $(10 \%)$ provided incentives to continue fortification (e.g., reduction of taxes for fortification premix).

Other gaps in documentation existed in regards to the cost of monitoring fortification and laboratory procedures (Table 2). For example, only 35\% stated consideration of the financial responsibility of monitoring and enforcing fortification (e.g., cost of laboratory testing; explicit budget for monitoring activities). Furthermore, only $19 \%$ of country-grain combinations stated that the cost of fortification is regulated through cost-sharing schemes between government and industry or reduced taxes for fortification inputs. Regarding laboratory procedures, while $60 \%$ of country-grain combinations referenced the required analytical assays for measuring nutrients in food, only $36 \%$ of country-grain combinations focused on the quantitative analysis of a marker micronutrient(s) such as iron, which limits the amount of laboratory analysis required but accurately assesses fortification since fortificants are typically added together in premix. Even fewer (11\%) explicitly recognized that laboratory results are subject to several sources of variation and do not alone provide conclusive evidence of compliance. Lastly, results showed that less than one-third $(31 \%)$ stated how government monitoring results are shared with stakeholders, including consumers.

A sensitivity analysis investigated differences between reviews that were considered complete (i.e., country representatives confirmed that all relevant documents were included in the reviews) versus those that were unconfirmed in regards to completeness (Supplement Table 2). We observed few differences between the subset of 23 reviews that were confirmed by country representatives and those that were not. Differences were noted for 5 of 44 items: stating the food vehicle to be fortified, describing the sampling process for internal

\section{Less than one- third of country- grain combinations stated how government monitoring results are shared with stakeholders.}


FIGURE 4. Median Country-Grain Combination Scores ${ }^{a}$ by Income Level in Countries With Mandatory CerealGrain Fortification

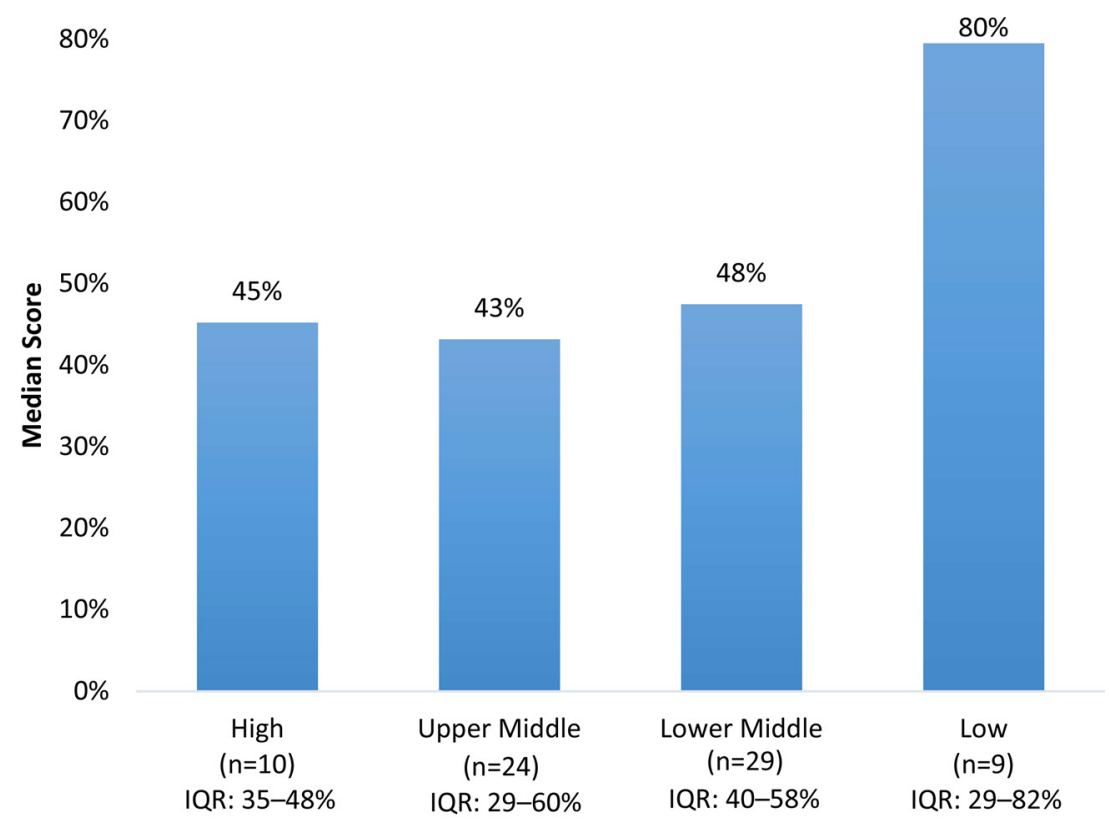

Income Level

Abbreviation: IQR, interquartile range.

${ }^{a}$ Country-grain combination refers to the unit of analysis; countries that mandate the fortification of multiple cereal grains will contribute more than one country-grain combination (e.g. Philippines-wheat and Philippines-rice). Scores based on number of checklist items fully documented out of total applicable checklist items.

monitoring, stating the applicability of qualitative testing in internal monitoring, clarifying roles and responsibilities in external monitoring, and requiring enforcement to include feedback to those monitored.

We identified what we considered excellent examples of each of the 44 checklist items from English-language and English-translated documents (Supplement Table 3). We compiled completed checklists for each country-grain combination, including extracted sample language from the documents reviewed (Supplement Table 4).

\section{Most countries \\ lack \\ documentation around the areas that would influence product compliance to national standard.}

systematically measure the documentation of each country-grain combination and to evaluate country policies against these criteria. We found that countries document the technical specifications for fortification, such as allowable food vehicles and nutrients required, and most document systems for internal, external, and import monitoring. However, documentation is lacking in some areas, such as describing the roles and responsibilities for monitoring between governmental agencies, providing detailed descriptions of protocols and systems for monitoring, addressing the costs of fortification and fortification monitoring, outlining enforcement strategies, and describing how government monitoring results are reported to stakeholders. Lack of documentation persisted largely around the areas that would influence product compliance to national standard, while sufficient documentation existed around areas that establish a mandatory program. This is important to highlight, as it is a more complex piece that needs to be carefully outlined (e.g., assigning clear roles and responsibilities for regulatory monitoring, 
TABLE 2. Percentage of Country-Grain Combinations ${ }^{a}$ With Documented Items in Fortification Legislation, Standards, and Monitoring Documents ( $\mathrm{N}=72$ )

\begin{tabular}{|c|c|c|c|c|}
\hline Item & $\begin{array}{l}\text { Eligible } \\
\text { (N) }\end{array}$ & $\begin{array}{l}\%(n) \\
\text { Fully Meeting }\end{array}$ & $\begin{array}{c}\%(n) \\
\text { Partly Meeting }\end{array}$ & $\begin{array}{c}\%(\mathbf{n}) \\
\text { Not Meeting }\end{array}$ \\
\hline \multicolumn{5}{|l|}{ General } \\
\hline 1. Food vehicle stated in legislation & 72 & $97 \%(70)$ & - & $3 \%(2)$ \\
\hline 2. Public health objective/purpose & 72 & $69 \%(50)$ & - & $31 \%(22)$ \\
\hline 3. Accepted international norms & 72 & $54 \%(39)$ & - & $46 \%(33)$ \\
\hline 4. Definitions specific to fortification & 72 & $76 \%(55)$ & - & $24 \%(17)$ \\
\hline 5. Repeals of prior documentation ${ }^{b}$ & 59 & $71 \%(42)$ & - & $29 \%(17)$ \\
\hline 6. Effective date/grace period & 72 & $72 \%(52)$ & - & $28 \%(20)$ \\
\hline \multicolumn{5}{|l|}{ Micronutrients/Premix } \\
\hline 7. Nutrients required & 72 & $100 \%(72)$ & - & $0 \%(0)$ \\
\hline 8. Fortificants (chemical compounds) & 72 & $88 \%(63)$ & - & $13 \%(9)$ \\
\hline 9. Fortification levels & 72 & $42 \%(30)$ & $54 \%(39)$ & $4 \%(3)$ \\
\hline 10. Bioavailability of fortificants & 72 & $31 \%(22)$ & - & $69 \%(50)$ \\
\hline 11. Nutrient stability & 72 & $54 \%(39)$ & - & $46 \%(33)$ \\
\hline \multicolumn{5}{|l|}{ Costing } \\
\hline 12. Cost sharing of fortification & 72 & $19 \%(14)$ & - & $81 \%(58)$ \\
\hline 13. Financial responsibility of monitoring and enforcement & 72 & $35 \%(25)$ & - & $65 \%(47)$ \\
\hline \multicolumn{5}{|l|}{ Labeling } \\
\hline 14. Labeling required & 72 & $78 \%(56)$ & - & $22 \%(16)$ \\
\hline 15. Guidance on health claims & 72 & $50 \%(36)$ & - & $50 \%(36)$ \\
\hline \multicolumn{5}{|l|}{ Internal Monitoring (conducted by industry during production) } \\
\hline 16. Sampling process outlined ${ }^{b}$ & 31 & $71 \%(22)$ & $29 \%(9)$ & $0 \%(0)$ \\
\hline 17. Industry QA/QC justified/required & 72 & $64 \%(46)$ & - & $36 \%(26)$ \\
\hline 18. Applicability of qualitative tests & 72 & $29 \%(21)$ & $1 \%(1)$ & $69 \%(50)$ \\
\hline \multicolumn{5}{|c|}{ External Monitoring (conducted by government at production sites) } \\
\hline 19. External monitoring justified & 72 & $64 \%(46)$ & - & $36 \%(26)$ \\
\hline 20. Protocols and systems described & 72 & $33 \%(24)$ & $28 \%(20)$ & $39 \%(28)$ \\
\hline 21. Roles and responsibilities clarified ${ }^{b}$ & 56 & $45 \%(25)$ & $7 \%(4)$ & $48 \%(27)$ \\
\hline 22. Timeline for inspections outlined & 72 & $26 \%(19)$ & $13 \%(9)$ & $61 \%(44)$ \\
\hline 23. Sampling process outlined ${ }^{b}$ & 45 & $67 \%(30)$ & $33 \%(15)$ & $0 \%(0)$ \\
\hline 24. Applicability of qualitative tests & 72 & $19 \%(14)$ & $1 \%(1)$ & $79 \%(57)$ \\
\hline 25. Registration requirements & 72 & $38 \%(27)$ & - & $63 \%(45)$ \\
\hline \multicolumn{5}{|c|}{ Commercial Monitoring (conducted by government at market or distribution sites) } \\
\hline 26. Commercial monitoring justified & 72 & $47 \%(34)$ & - & $53 \%(38)$ \\
\hline 27. Protocols and systems described & 72 & $19 \%(14)$ & $21 \%(15)$ & $60 \%(43)$ \\
\hline 28. Roles and responsibilities clarified ${ }^{b}$ & 63 & $32 \%(20)$ & $0 \%(0)$ & $68 \%(43)$ \\
\hline 29. Timeline for inspections outlined ${ }^{b}$ & 44 & $14 \%(6)$ & $25 \%(11)$ & $61 \%(27)$ \\
\hline 30. Sampling process outlined ${ }^{b}$ & 28 & $71 \%(20)$ & $29 \%(8)$ & $0 \%(0)$ \\
\hline
\end{tabular}


TABLE 2. Continued

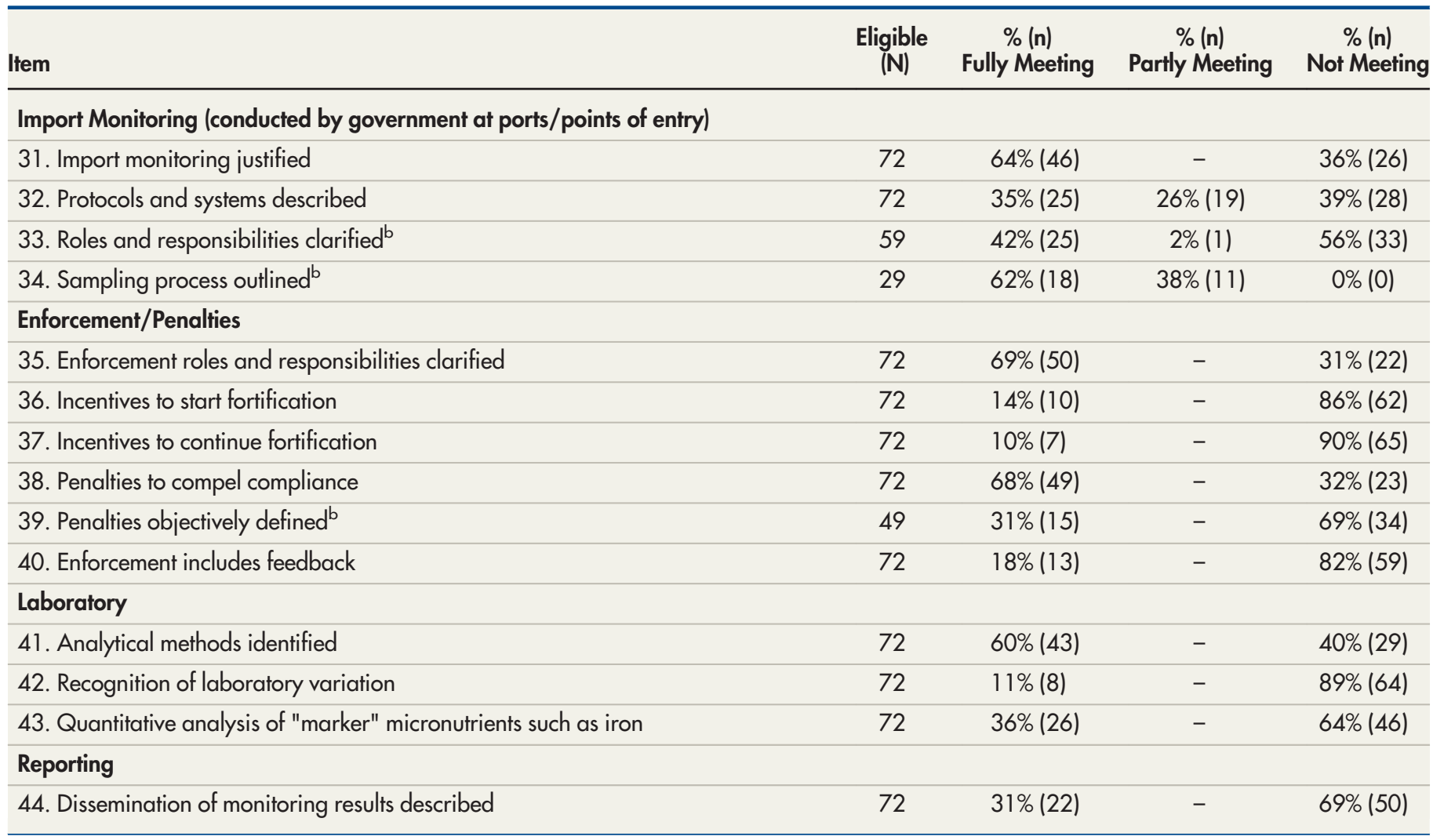

Abbreviations: QA/QC, quality assurance/quality control.

${ }^{a}$ Country-grain combination refers to the unit of analysis; countries that mandate the fortification of multiple cereal grains will contribute more than one country-grain combination (e.g., Philippines-wheat and Philippines-rice).

b The number eligible differs for these items due to a "not applicable" option on the scoring checklist.

establishing detailed protocols for conducting regulatory monitoring) if a program is going to be monitored for long-term adherence and impact. ${ }^{7,21}$ Given these gaps, our checklist could be used as a guide to strengthen existing documentation or assist in developing new documentation, as this would ensure important areas, such as product compliance, are outlined.

Our study found similar results as a review of legislative frameworks for corn flour and maize meal fortification. ${ }^{8}$ Similar to our study, Makhumula and colleagues found that legislative and standards documents commonly describe fortificants used, fortification labeling, reference analytical assays, and sampling procedures. ${ }^{8}$ In our review, $100 \%(\mathrm{n}=1 \mathrm{l})$ of maize flour countries documented the fortificants to be used and $91 \%(n=10)$ of maize flour countries clearly labeled their maize flour as fortified. Of the 4 maize flour countries that stated the use of sampling in external and import monitoring, 3 provided details on sampling procedures for external and import monitoring. The majority of maize flour countries referenced the required analytical assays for nutrients $(73 \%, \mathrm{n}=8)$ in our review. Differences observed might be because the checklist for our study was specific to fortification, whereas Makhumula and colleagues' review was not limited to fortification. In particular, this might explain any differences observed in sampling procedures and analytical assays; sampling and laboratory testing could include food safety parameters in Makhumula and colleagues' review.

One notable conclusion from Makhumula and colleagues was that countries fortifying maize flour take a variety of approaches to setting fortification levels, such as specifying the minimum amount required or an allowable range. ${ }^{8}$ In our study, a slight majority $(55 \%, \mathrm{n}=6)$ of maize flour countries provide a range or a 
single number within an allowable range, while $45 \%(n=5)$ of countries provide a single number only. Opposing results were found for wheat flour and rice in this study: $40 \%(n=22)$ of wheat flour and $33 \%(n=2)$ of rice countries provide a range or single number within an allowable range, while $53 \%(\mathrm{n}=29)$ of wheat flour and $67 \%(n=4)$ of rice countries provide a single number only (the remaining $7 \% \quad(n=4)$ of wheat flour countries did not state fortification levels). These results confirm Makhumula's maize flour findings and suggest there are inconsistencies between food vehicles and countries in stating fortification levels, and clarity is needed on this issue.

A 2015 survey by Luthringer and colleagues highlights the gap between legislation, standards, and monitoring documents and barriers in the monitoring of fortified foods identified by regulatory agencies and the food industry. ${ }^{7}$ Gaps identified in the documentation reviewed in our study support the survey results reported by Luthringer et al. For example, when asked in the survey to prioritize regulatory monitoring elements needing improvement to ensure compliance against national fortification standards, industry respondents prioritized incentives and penalties for enforcement, both areas of weakness in the documentation reviewed in our study (only 10\% of documentation stated incentives are offered to continue fortification and $21 \%$ objectively defined penalties). While incentives are rarely documented, Luthringer and colleagues' study suggests that both regulatory agency and industry respondents believed that incentives could encourage compliance with fortification regulations. Survey results also indicated that only slightly more than half of regulatory agencies report regularly sharing their data with stakeholders. In the documentation reviewed in our study, only $31 \%$ of country-grain combinations require government monitoring results to be reported. Together, these results suggest that few countries require results to be reported, while slightly more claim to report results. The benefits of a requirement to report results could be written into official documentation, compelling the reporting of results to stakeholders and creating an accountability structure. Lastly, Luthringer et al.'s study identified the lack of clarity in the roles of government authorities as a barrier to effective monitoring; our study found a similar lack of clarity in the documentation. ${ }^{7}$ When two or more agencies were involved, roles and responsibilities were only clarified in $32 \%$ to $45 \%$ of documentation, dependent on monitoring type, indicating that this is an area of documentation that could be strengthened. On the whole, the opinions expressed by regulatory agency and industry respondents in the survey conducted by Luthringer et al. are confirmed by the present study. Not only do the survey respondents think that documentation is unclear but also our study confirms that documentation is generally lacking in the areas identified by the survey respondents.

While our study aligns with previous studies of fortification legislation, standards, and monitoring documents, it also highlights concerns that previous studies have not raised. ${ }^{7,8,10,21,23,24}$ For instance, the majority of previous studies have not reviewed the content of monitoring documents. ${ }^{7,8,10,24}$ Our study found that the details included in monitoring documents vary widely-some countries do not have any monitoring procedures in their dossier of documentation, while other countries have a unique manual for each type of monitoring. In particular, our study identifies the lack of documented protocols and systems in external, commercial, and import monitoring (39\%, 60\%, and 39\%, respectively). Our study corroborates a previous study by van den Wijngaart et al. $(2013)^{21}$ that identified the issue of poorly established or weakly designed protocols and systems for regulatory monitoring of salt and wheat flour fortification in countries of the Association of Southeast Asian Nations (ASEAN); our study found that for the 3 types of regulatory monitoring, $21 \%$ to $28 \%$ of country-grain combinations did not explicitly describe their monitoring protocols (scored as "partly meeting"). While the van den Wijngaart et al. study and our study are in agreement about the variable quality of monitoring procedures, our study notes the complete lack of documentation. This finding emphasizes the opportunity to improve upon existing monitoring procedures and the opportunity to implement well-designed monitoring procedures for the first time. Additionally, our study shows infrequent documentation requiring qualitative (spot) tests in internal $(29 \%)$ and external monitoring $(19 \%)$. While it is possible that spot tests are used but not documented in monitoring procedures, this result shows an opportunity to expand the use of this simple, fast, and inexpensive method. $^{11}$

\section{Strengths and Limitations}

First, an important strength of our study is that such a comprehensive review for any cereal grain and for any fortified food has not previously been

\section{There is a lack of documented protocols and systems in external, commercial, and import monitoring.}


done. Previous efforts have focused on reviewing legislation and/or standards, while few have included monitoring documents; our study included all 3 types of documents for a more complete sense of content. Furthermore, each country in our study was objectively scored using a standardized checklist of key items in official fortification legislation, standards, and monitoring documents by two separate reviewers. Other strengths of our study are the inclusion of documents from $84 \%$ of countries ( 68 of 81 countries) that mandated cereal-grain fortification as of January 31, 2015, regardless of the language of the document, and the examination of multiple food vehicles within the cereal-grain family. The checklist we created for this study can be used by countries as a framework for starting a new fortification program or assessing a current fortification program. An additional strength is that this methodology presents a model with which to expand this research to other food vehicles, such as salt and vegetable oils.

The main limitation of our study is the possibility of missing documentation. However, attempts were made to collect missing documentation from country representatives, and a sensitivity analysis showed few differences between those countries where country representatives confirmed documentation and those who did not. It was assumed that the knowledge of and access to documents was complete and up to date for the country representatives that were reached. Furthermore, selection bias may be an issue, as those countries that were excluded due to a lack of documentation likely have less comprehensive legislation, standards, and/or monitoring guidelines than those included. This bias may be particularly problematic when comparing scores by region, as there were 7 excluded countries from the Middle East region (78\% of countries in the region), 5 from Africa $(22 \%)$, and 1 from Asia $(25 \%)$. It is possible that some details were lost in the translation of the documents into English from some languages, but few documents were not already in English or Spanish. Furthermore, it is possible that the checklist was incomplete and did not include some important items that countries prioritize in their documents. However, this risk is low and was mitigated through an inclusive process of listing, refining, and prioritizing the items by considering the existing literature, expert opinion, and through pilot testing for other items that were in reviewed documents. Lastly, our study only addresses documentation, not implementation; while it seems plausible that countries with good documentation also have good implementation of that documentation (and vice-versa), our study did not address implementation of the documentation reviewed.

\section{CONCLUSION}

In conclusion, our comprehensive review of 72 country-grain combinations found that the majority adequately document the required food vehicles, nutrients, and amounts of fortificants for fortification. Most countries have documented justification of the need for monitoring, but detailed protocols, roles and responsibilities for monitoring between agencies, and systems are not well defined. Furthermore, few countries document strategies for paying for the cost of fortification or alleviating the burden on industry through tax exemption or other economic incentives, which can be important in ensuring the sustainability and success of a fortification program. By identifying areas that are often weak or absent in legislation, standards, and monitoring documents, countries with existing mandatory fortification can improve upon these items in revisions to their documents, while countries that are new to fortification will have a better sense of what to include in their policies and programs from the beginning.

Going forward, this study's checklist can be used by many stakeholders. The in-country representatives of private, civic, and public sectors who oversee fortification activities can use the checklist to assess and revise the documents that guide their country's programs. Organizations that provide technical assistance to countries can use the checklist to find common themes across countries and offer technical assistance through regional workshops, for example, or targeted technical assistance based on countries' specific needs.

Funding: Kristin Marks's time was supported by the Food Fortification Initiative. Corey Luthringer's time was supported by an agreement between GAIN and the Bill \& Melinda Gates Foundation. Laird Ruth's time was supported by an agreement between the United States Centers for Disease Control and Prevention (CDC) and McKing Consulting Corporation. Laura Rowe's time was supported by Project Healthy Children. Noor Khan's and Luz Maria De-Regil's time was supported by agreements between Nutrition International and Global Affairs Canada and the Department for International Development UK. Ximena López's time was supported by Granotec Foundation. Helena Pachón's time was supported by an agreement between the United States Centers for Disease Control and Prevention (CDC), McKing Consulting Corporation, and Emory University.

Disclaimer: The findings and conclusions of this article are those of the authors and do not necessarily represent the official position of the U.S. Centers for Disease Control and Prevention.

Competing Interests: None declared. 
REFERENCES

1. Allen L, de Benoist B, Dary O, Hurrell RF, eds. Guidelines on Food Fortification With Micronutrients. Geneva: World Health Organization and Food and Agriculture Organization; 2006. http://www.who.int/nutrition/publications/guide_food fortification_micronutrients.pdf. Accessed April 18, $201 \overline{8}$.

2. Blencowe H, Cousens S, Modell B, Lawn J. Folic acid to reduce neonatal mortality from neural tube disorders. Int J Epidemiol. 2010;39 (suppl 1):i110-i121. CrossRef. Medline

3. Atta CAM, Fiest KM, Frolkis $A D$, et al. Global birth prevalence of spina bifida by folic acid fortification status: a systematic review and meta-analysis. Am J Public Health. 2016;106(1):e24-e34. CrossRef. Medline

4. Food Fortification Initiative (FFI). Defeating Anemia: 2015 Year in Review. Atlanta, GA: FFl; 2016. http://www. ffinetwork.org/about/ stay_informed/publications/documents/FFI2015Review.pdf. Accessed April 18, 2018.

5. Food Fortification Initiative (FFI). Say Hello to a Fortified Future: 2016 Year in Review. Atlanta, GA: FFl; 2017. http://ffinetwork.org/ about/stay_informed/publications/documents/FFI2016Review. pdf. Accessed April 18, 2018.

6. Zimmerman S, Baldwin R, Codling K, et al. Mandatory policy: most successful way to maximize fortification's effect on vitamin and min eral deficiency. Indian J Comm Health. 2014;26(suppl S2):369374. http://www.iapsmupuk.org/journal/index.php/IJCH/ article/view/958. Accessed April 18, 2018

7. Luthringer CL, Rowe LA, Vossenaar M, Garrett GS. Regulatory monitoring of fortified foods: identifying barriers and good practices. Glob Health Sci Pract. 2015;3(3):446-461. CrossRef. Medline

8. Makhumula P, Dary O, Guamuch M, Tom C, Afidra R, Rambeloson Z. Legislative frameworks for corn flour and maize meal fortification. Ann N Y Acad Sci. 2014;1312(1):91-104. CrossRef. Medline

9. Allen LH. New approaches for designing and evaluating food fortification programs. J Nutr. 2006;136(4):1055-1058. CrossRef. Medline

10. Dijkhuizen MA, Wieringa FT, Soekarjo D, Van KT, Laillou A. Legal framework for food fortification: examples from Vietnam and Indonesia. Food Nutr Bull. 2013;34(2_suppl):S1 12-S1 23. CrossRef. Medline

11. Flour Millers Toolkit. Food Fortification Initiative website. http:// www.ffinetwork.org/implement/toolkit.html. Accessed April 18, 2018.

12. Forsman C, Milani P, Schondebare JA, Matthias D, Guyondet C. Rice fortification: a comparative analysis in mandated settings. Ann NY Acad Sci. 2014;1324(1):67-81. CrossRef. Medline

13. Gayer J, Smith G. Micronutrient fortification of food in Southeast Asia: recommendations from an expert workshop. Nutrients. 2015;7 (12):646-658. CrossRef. Medline

14. Hemenway D. Monitoring and Compliance: The Political Economy of Inspection. Greenwich, CT: JAI Press; 1985. CrossRef

15. Isabelle M, Chan P, Wijaya SY. Report on Regulatory Status of Micronutrient Fortification in Southeast Asia. Singapore: International Life Sciences Institute Southeast Asian Region; 2011. http://ilsi.org/publication/report-on-regulatory-status-ofmicronutrient-fortification-in-southeast-asia/. Accessed April 18, 2018.

16. Lawrence M. Challenges in translating scientific evidence into mandatory food fortification policy: an antipodean case study of the folate-neural tube defect relationship. Public Health Nutr. 2005;8 (8):1235-1241. CrossRef. Medline

17. Nathan R. Regulation of fortified foods to address micronutrient malnutrition: legislation, regulations and enforcement. 3rd ed. Ottawa, Canada: Micronutrient Initiative; 1999. http://ffinetwork. org/documents/Legislation_Manual.pdf. Accessed April 18, 2018.

18. Peña-Rosas JP, Parvanta I, Van Der Haar F, Chapel TJ. Monitoring and evaluation in flour fortification programs: design and implementation considerations. Nutr Rev. 2008;66(3):148-162. CrossRef. Medline

19. Sullivan KM. The challenges of implementing and monitoring of salt iodisation programmes. Best Pract Res Clin Endocrinol Metab. 2010;24(1):101-106. CrossRef. Medline

20. Tan KYM, Beek EM, Chan MY, Zhao X, Stevenson L. Health claims on food products in Southeast Asia: regulatory frameworks, barriers, and opportunities. Nutr Rev. 2015;73(9):634-641. CrossRef. Medline

21. van den Wijngaart A, Bégin F, Codling K, Randall P, Johnson QW. Regulatory monitoring systems of fortified salt and wheat flour in selected ASEAN countries. Food Nutr Bull. 2013;34(2_suppl):S102S111. CrossRef. Medline

22. Vapnek J, Spreij M. Perspectives and Guidelines on Food Legislation, With a New Model Food Law. Rome: Food and Agriculture Organization of the United Nations; 2005. http://www.fao.org/3/ a-a0274e.pdf. Accessed April 18, 2018.

23. Wirth J, Nichols E, Masd H, Barham R, Johnson Q, Serdula M. External mill monitoring of wheat flour fortification programs: an approach for program managers using experiences from Jordan. Nutrients. 2013;5(12):4741-4759. CrossRef. Medline

24. UNICEF East Asia and Regional Office (EAPRO). Review of National Legislation for Universal Salt lodisation: South and East Asia and the Pacific. Bangkok: UNICEF EAPRO; 2015. https://www.unicef.org/ eapro/Universal_Salt_lodisation_in_South_and_East_Asia_and_ Pacific.pdf.

25. Caribbean Community Secretariat. Specification for wheat flour Caribbean Community Standard. CCS 0024: 1992. Barbados, WI: CARICOM Export Development Project; Georgetown, Guyana: Caribbean Community Secretariat. 1995

26. Food Fortification Initiative (FFI). New Grain, New Name: 2014 Year in Review. Atlanta, GA: FFl; 2015. http://www. ffinetwork.org/ about/stay_informed/publications/documents/FFI2014Review. pdf. Accessed April 18, 2018.

27. Regional Activity. Food Fortification Initiative website. http:// ffinetwork.org/regional_activity/. Accessed April 18, 2018.

28. World Bank Country and Lending Groups. World Bank website. https://datahelpdesk.worldbank.org/knowledgebase/articles/ 906519-world-bank-country-and-lending-groups. Accessed April $18,2018$.

\section{Peer Reviewed}

Received: November 20, 2017; Accepted: February 13, 2018

Cite this article as: Marks KJ, Luthringer CL, Ruth L, et al. Review of grain fortification legislation, standards, and monitoring documents. Glob Health Sci Pract. 2018;6(2):356-371. https://doi.org/10.9745/GHSP-D-17-00427

(c) Marks et al. This is an open-access article distributed under the terms of the Creative Commons Attribution 4.0 International License (CC BY 4.0), which permits unrestricted use, distribution, and reproduction in any medium, provided the original author and source are properly cited. To view a copy of the license, visit http://creativecommons.org/licenses/by/4.0/. When linking to this article, please use the following permanent link: https://doi.org/10.9745/GHSP-D$17-00427$ 